\title{
Investigation on the Transition Criterion of Smooth Stratified Flow to Other Flow Patterns for Gas-Hydrate Slurry Flow
}

\author{
Bohui Shi, Jiaqi Wang, Yifan Yu, Lin Ding, Yang Liu, and Haihao Wu \\ National Engineering Laboratory for Pipeline Safety, MOE Key Laboratory of Petroleum Engineering, Beijing Key Laboratory of \\ Urban Oil and Gas Distribution Technology, China University of Petroleum-Beijing, Changping, Beijing 102249, China
}

Correspondence should be addressed to Bohui Shi; bh.shi@cup.edu.cn

Received 14 November 2016; Revised 6 February 2017; Accepted 27 March 2017; Published 2 May 2017

Academic Editor: Jerzy Baldyga

Copyright (C) 2017 Bohui Shi et al. This is an open access article distributed under the Creative Commons Attribution License, which permits unrestricted use, distribution, and reproduction in any medium, provided the original work is properly cited.

A stability criterion for gas-hydrate slurry stratified flow was developed. The model was based on one-dimensional gas-liquid twofluid model and perturbation method, considering unstable factors including shear stress, gravity, and surface tension. In addition, mass transfer between gas and liquid phase caused by hydrate formation was taken into account by implementing an inward and outward natural gas hydrates growth shell model for water-in-oil emulsion. A series of gas-hydrate slurry flow experiments were carried out in a high-pressure ( $>10 \mathrm{MPa}$ ) horizontal flow loop. The transition criterion of smooth stratified flow to other flow patterns for gas-hydrate slurry flow was established and validated and combined with experimental data at different water cuts. Meanwhile, parameters of this stability criterion were defined. This stability criterion was proved to be efficient for predicting the transition from smooth to nonsmooth stratified flow for gas-hydrate slurry.

\section{Introduction}

Gas hydrates are ice-like crystals formed by inclosing gas molecules (guests) in clathrates of water molecules (host) under high pressure and low temperature [1]. Gas hydrates are known to cause blockage in oil and gas transportation pipelines [2]. With the tendency of offshore oil industry towards deeper water, gathering systems are confronting unprecedented flow assurance challenges on hydrate formation and plugging. Safety has become an unparalleled problem in offshore oil and gas facilities under undulating terrain condition, especially for high-pressure and low temperature operation conditions owing to the risk of hydrate blockage.

Conventionally, chemical-based injection and insulation are two major techniques to prevent hydrate plugging in offshore production pipelines. However, these two techniques are of high capital expenditure and technical limitations $[1,3]$. Recently, hydrate slurry technique has turned out to be a new option to avoid hydrate blocking. In this method, hydrates are not prevented from formation but are made transportable suspending in liquid phase under complex multiphase flow condition [4-9]. Obviously, multiphase flow analysis is an important factor for implementing hydrate slurry technique in deep water petroleum explorations and developments.

Flow pattern is the key issue in characterizing multiphase flow. There are two generally recognized methods for flow pattern determination: plotting flow pattern map according to the experimental data [10-13] and establishing flow pattern transition criterion based on flow mechanism [14-16]. These two methods have been widely implemented in gas-liquid two-phase flow. However, the flow would be much too complicated, when hydrate forms in the liquid phase.

Though lots of investigations have been made on thermodynamic and kinetic of gas-hydrate formation and decomposition [17-24], study on multiphase flow of gas-hydrate slurry is far from sufficient. Tajima et al. [25] observed $\mathrm{CO}_{2}$ hydrate slurry flow patterns in $\mathrm{CO}_{2}$-water two-phase flow using different types of static mixers. Zerpa et al. [26] and Joshi et al. [27] proposed a conceptual model for hydrate plug formation mechanism in water-dominated system, where gas-liquid and liquid-solid flow pattern were defined and characteristics of flow pattern transition with increasing of hydrates volume fraction were studied. Zhao [28] and Gong et al. $[7,8]$ numerically simulated gas-hydrate slurry stratified 


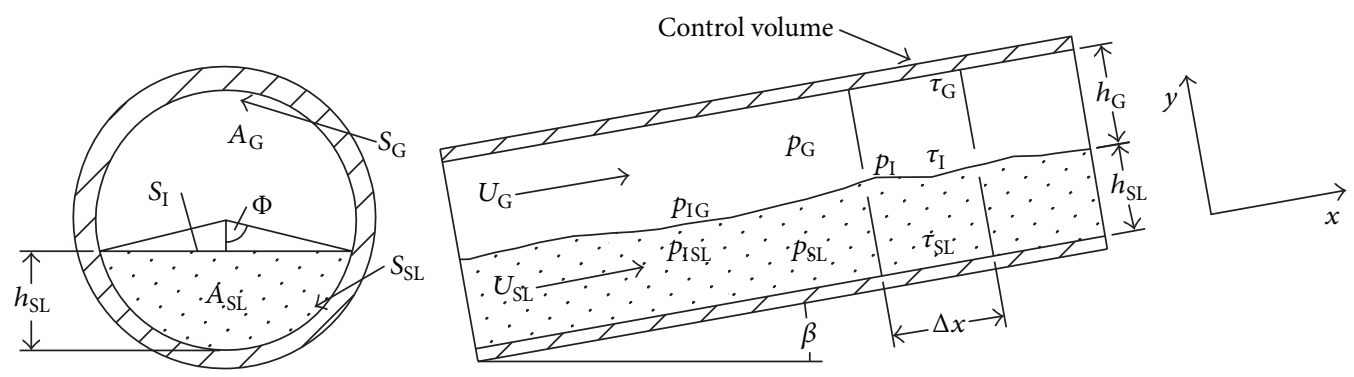

FIGURE 1: Sectional geometry of gas-hydrate slurry stratified flow.

flow, and Kwon et al. [29] simulated the oil-gas-water-hydrate annular-mist flow. Ding et al. [30] reported the difference of the flow patterns with and without hydrates. And, it was concluded that hydrates formation resulted in the decrease of stratified smooth flow area on flow map and less stability of stratified smooth flow. However, little attention has been paid to the flow pattern transition criterion of gas-hydrate slurry flow, especially the stability criterion of stratified flow.

In this paper, gas-hydrate slurry interface stability was analyzed by deriving dispersion function of the interface wave, and then the transition criterion from smooth stratified flow to other flow patterns was obtained. Thereafter, a set of gas-hydrate slurry flow experiments in high-pressure ( $>10 \mathrm{MPa}$ ) horizontal flow loop were carried out to investigate the flow pattern characteristics of gas-hydrate slurry flow. The transition criterion of smooth stratified flow to other flow patterns for gas-hydrate slurry flow was established and validated, combined with experimental data at different water cuts.

\section{Model Development}

A one-dimensional two-fluid model describing gas-hydrate slurry stratified flow was developed. The schematic description is shown in Figure 1. In this work, the slurry phase was simplified as incompressible. Moreover, work exchange between the fluid and the environment as well as temperature change caused by hydrates formation was ignored.

In Figure $1, h_{\mathrm{G}}$ and $h_{\mathrm{SL}}$ represent the height of gas phase and hydrate slurry phase, $A_{\mathrm{G}}$ and $A_{\mathrm{SL}}$ represent the cross section area of gas phase and hydrate slurry phase, $U_{\mathrm{G}}$ and $U_{\mathrm{SL}}$ represent velocity of gas phase and hydrate slurry phase, $\tau_{\mathrm{G}}, \tau_{\mathrm{SL}}$, and $\tau_{\mathrm{I}}$ are shear friction at interface of gas phasepipe wall, hydrate slurry-pipe wall, and gas-hydrate slurry phase, $S_{\mathrm{G}}, S_{\mathrm{SL}}$, and $S_{\mathrm{I}}$ represent wetted perimeter of gas phase, hydrate slurry phase, and gas-hydrate slurry interface, $p_{\mathrm{G}}, p_{\mathrm{SL}}$, and $p_{\mathrm{I}}$ represent pressure of gas phase, hydrate slurry phase, and pressure at the interface, $p_{\mathrm{IG}}$ and $p_{\mathrm{ISL}}$ represent relative pressure at the interface of gas phase and hydrate slurry phase, $\beta$ represents angle of inclination, $\Delta x$ represents distance to the infinitesimal segment, and $x$ and $y$ represent axial and radial direction of the pipe. In addition, the cross section geometry can be found in the supporting information document in Supplementary Material available online at https://doi.org/10.1155/2017/9846507 (cross section geometry).

\subsection{Flow Analysis}

2.1.1. Continuity Equation. For the gas-hydrate slurry stratified flow shown in Figure 1, continuity equation for each phase can be derived as follows:

$$
\begin{gathered}
\frac{\partial}{\partial t}\left(\rho_{\mathrm{G}} A_{\mathrm{G}}\right)+\frac{\partial}{\partial x}\left(\rho_{\mathrm{G}} A_{\mathrm{G}} U_{\mathrm{G}}\right)=\Gamma A, \\
\frac{\partial}{\partial t}\left(\rho_{\mathrm{SL}} A_{\mathrm{SL}}\right)+\frac{\partial}{\partial x}\left(\rho_{\mathrm{SL}} A_{\mathrm{SL}} U_{\mathrm{SL}}\right)=-\Gamma A,
\end{gathered}
$$

where $\rho_{\mathrm{G}}$ and $\rho_{\mathrm{SL}}$ are densities of gas and hydrate slurry phase, $A$ represents overall cross section area, and $\Gamma$ represents mass transfer rate, which is sectional average weight of gas transferred from gas to liquid per second for hydrate formation. The mass transfer rate, $\Gamma$, can be estimated using the inward and outward gas-hydrate growth shell model [23], since this model was developed to describe the hydrates formation in water-in-oil emulsion system. The process of hydrates nucleating, forming, and growing as shell covering the water droplets suspended in the continuous liquid phase can be simulated. And, this inward and outward gas-hydrate growth shell model is proved suitable and preferred to be applied in the hydrates slurry flow for the calculation of hydrates fraction and gas consumption. And, the application of this hydrate growth shell model is available in the supporting information (Hydrate Growth Model Implementation).

By introducing slurry phase height $h_{\mathrm{SL}}$, which is a key parameter for stratified flow, (1a) and (1b) can be transformed into (2a) and (2b) as function of $h_{\mathrm{SL}}$.

$$
\begin{gathered}
\frac{\partial\left(\rho_{\mathrm{G}} h_{\mathrm{SL}}\right)}{\partial t}-\frac{A_{\mathrm{G}}}{A_{\mathrm{SL}}^{\prime}} \frac{\partial\left(\rho_{\mathrm{G}} U_{\mathrm{G}}\right)}{\partial x}+\rho_{\mathrm{G}} U_{\mathrm{G}} \frac{\partial h_{\mathrm{SL}}}{\partial x}=-\frac{\Gamma A}{A_{\mathrm{SL}}^{\prime}} \\
\frac{\partial\left(\rho_{\mathrm{SL}} h_{\mathrm{SL}}\right)}{\partial t}+\frac{A_{\mathrm{SL}}}{A_{\mathrm{SL}}^{\prime}} \frac{\partial\left(\rho_{\mathrm{SL}} U_{\mathrm{SL}}\right)}{\partial x}+\rho_{\mathrm{SL}} U_{\mathrm{SL}} \frac{\partial h_{\mathrm{SL}}}{\partial x}=-\frac{\Gamma A}{A_{\mathrm{SL}}^{\prime}}
\end{gathered}
$$

where $A_{\mathrm{SL}}^{\prime}=d A_{\mathrm{SL}} / h_{\mathrm{SL}}$. 
2.1.2. Momentum Balance Equation. Momentum balance for each phase can be described as follows:

$$
\begin{gathered}
\frac{\partial\left(\rho_{\mathrm{G}} A_{\mathrm{G}} U_{\mathrm{G}}\right)}{\partial t}+\frac{\partial\left(\rho_{\mathrm{G}} A_{\mathrm{G}} U_{\mathrm{G}}^{2}\right)}{\partial x}-\Gamma A U_{\mathrm{G}} \\
=-\tau_{\mathrm{G}} S_{\mathrm{G}}-\tau_{\mathrm{I}} S_{\mathrm{I}}-\rho_{\mathrm{G}} g A_{\mathrm{G}} \sin \beta-A_{\mathrm{G}} \frac{\partial p_{\mathrm{IG}}}{\partial x} \\
\quad-A_{\mathrm{G}} \rho_{\mathrm{G}} g \cos \beta \frac{\partial h_{\mathrm{SL}}}{\partial x}, \\
\frac{\partial\left(\rho_{\mathrm{SL}} A_{\mathrm{SL}} U_{\mathrm{SL}}\right)}{\partial t}+\frac{\partial\left(\rho_{\mathrm{SL}} A_{\mathrm{SL}} U_{\mathrm{SL}}^{2}\right)}{\partial x}+\Gamma A U_{\mathrm{G}} \\
=-\tau_{\mathrm{SL}} S_{\mathrm{SL}}+\tau_{\mathrm{I}} S_{\mathrm{I}}-\rho_{\mathrm{SL}} g A_{\mathrm{SL}} \sin \beta-A_{\mathrm{SL}} \frac{\partial p_{\mathrm{ISL}}}{\partial x} \\
-A_{\mathrm{SL}} \rho_{\mathrm{SL}} g \cos \beta \frac{\partial h_{\mathrm{SL}}}{\partial x} .
\end{gathered}
$$

Assuming the interface to be flat in radial direction [31] and ignoring the influence of shorter waves on flow stability [32], the pressure difference at the interface can be approximated as

$$
P_{\mathrm{IG}}-P_{\mathrm{ISL}}=\sigma \frac{\partial^{2} h_{\mathrm{SL}}}{\partial x^{2}},
$$

where $\sigma$ represents interfacial tension and is considered constant in the control volume.

Interfacial shear stress $\tau_{\text {I }}$ consists of smooth interface shear stress and instability contribution. The following method, (5a) and (5b), is used in this work [33] to determine interfacial shear stress $\tau_{\mathrm{I}}$, introducing a correlated coefficient $C_{h}$

$$
\begin{aligned}
\tau_{\mathrm{I}}= & f_{\mathrm{I}} \rho_{\mathrm{f}} \frac{\left(U_{\mathrm{G}}-U_{\mathrm{SL}}\right)\left|U_{\mathrm{G}}-U_{\mathrm{SL}}\right|}{2} \\
& +\rho_{\mathrm{f}}\left(U_{\mathrm{G}}-U_{\mathrm{SL}}\right)^{2} C_{h} \frac{\partial h_{\mathrm{SL}}}{\partial x}, \\
f_{\mathrm{I}}= & \xi_{\mathrm{I}}\left[\left(\frac{S_{\mathrm{I}}}{\pi}\right) \frac{U_{\mathrm{f}} \rho_{\mathrm{f}}}{\mu_{\mathrm{f}}}\right]^{-\eta_{\mathrm{I}}},
\end{aligned}
$$

where $\rho_{\mathrm{f}}, U_{\mathrm{f}}$, and $\mu_{\mathrm{f}}$ refer to corresponding density, velocity, and viscosity of the phase with higher velocity and subscript f represents $G$ or SL according to the specific situation. Interfacial frication factor $f_{\mathrm{I}}$ can be calculated after obtaining empirical parameters $\xi_{\mathrm{I}}$ and $\eta_{\mathrm{I}}$ through experiments.

Substituting (4) and (5a) and (5b) into (3a) and (3b), the key equation of momentum balance relationship can be obtained as follows:

$$
\begin{gathered}
\frac{\partial\left(\rho_{\mathrm{G}} U_{\mathrm{G}}\right)}{\partial t}-\frac{\partial\left(\rho_{\mathrm{SL}} U_{\mathrm{SL}}\right)}{\partial t}+\frac{\partial\left(\rho_{\mathrm{G}} U_{\mathrm{G}}^{2}\right)}{\partial x}-\frac{\partial\left(\rho_{\mathrm{SL}} U_{\mathrm{SL}}^{2}\right)}{\partial x} \\
-U_{\mathrm{G}} \Gamma\left(\frac{1}{R_{\mathrm{SL}}}+\frac{1}{R_{\mathrm{G}}}\right)+\Pi \frac{\partial h_{\mathrm{SL}}}{\partial x}+\sigma \frac{\partial^{3} h_{\mathrm{SL}}}{\partial x^{3}}=F,
\end{gathered}
$$

$$
\begin{aligned}
\Pi & =\rho_{\mathrm{f}}\left(U_{\mathrm{G}}-U_{\mathrm{SL}}\right)^{2} C_{h} S_{\mathrm{I}}\left(\frac{1}{A_{\mathrm{G}}}+\frac{1}{A_{\mathrm{SL}}}\right) \\
& -\left(\rho_{\mathrm{SL}}-\rho_{\mathrm{G}}\right) g \cos \beta, \\
F & =\frac{\tau_{\mathrm{SL}} S_{\mathrm{SL}}}{A_{\mathrm{SL}}}-\frac{\tau_{\mathrm{G}} S_{\mathrm{G}}}{A_{\mathrm{G}}} \\
& -f_{\mathrm{I}} \rho_{\mathrm{f}} \frac{\left(U_{\mathrm{G}}-U_{\mathrm{SL}}\right)\left|U_{\mathrm{G}}-U_{\mathrm{SL}}\right|}{2} S_{\mathrm{I}}\left(\frac{1}{A_{\mathrm{G}}}+\frac{1}{A_{\mathrm{SL}}}\right) \\
& +\left(\rho_{\mathrm{SL}}-\rho_{\mathrm{G}}\right) g \sin \beta,
\end{aligned}
$$

where $R_{\mathrm{SL}}=A_{\mathrm{SL}} / A$ and $R_{\mathrm{G}}=A_{\mathrm{G}} / A$ refer to liquid holdup and void fraction, respectively. For steady state, $F=0$, (6a), (6b), and (6c) reduce to steady-state momentum equation.

Gas and hydrate slurry shear stresses at the pipe wall can be expressed as (7a) and (7b) by introducing fanning friction factor.

$$
\begin{gathered}
\tau_{\mathrm{G}}=\frac{1}{2} f_{\mathrm{G}} \rho_{\mathrm{G}} U_{\mathrm{G}}\left|U_{\mathrm{G}}\right|, \\
\tau_{\mathrm{SL}}=\frac{1}{2} f_{\mathrm{SL}} \rho_{\mathrm{SL}} U_{\mathrm{SL}}\left|U_{\mathrm{SL}}\right| .
\end{gathered}
$$

For gas phase, the following methods as (8a) and (8b) are applied for friction coefficient $f_{\mathrm{G}}$.

$$
\begin{aligned}
& f_{\mathrm{G}}=\frac{16}{\operatorname{Re}_{\mathrm{G}}}, \text { laminar flow where } \mathrm{Re}_{\mathrm{G}}<2300, \\
& f_{\mathrm{G}}=\frac{0.07725}{\left[\log \left(\operatorname{Re}_{\mathrm{G}} / 7\right)\right]^{2}},
\end{aligned}
$$

turbulent flow where $\operatorname{Re}_{\mathrm{G}} \geq 2300$.

For hydrate slurry phase, a friction coefficient method, (9) [34], is used, considering the influence of liquid flow as well as hydrate formation and agglomeration.

$$
\begin{aligned}
f_{\mathrm{SL}}= & {\left[4 \log \left(\frac{D_{\mathrm{SL}}}{2 \varepsilon_{\mathrm{f}}}\right)+3.48\right]^{-2} } \\
& +47 \frac{\rho_{\mathrm{H}}}{\rho_{\mathrm{L}}}\left[\left(\frac{\psi_{\max }}{\psi_{\mathrm{h}}}\right)^{1 / 3}-1\right]^{-2}\left(\frac{d_{\mathrm{p}}}{D_{\mathrm{SL}}}\right)^{2},
\end{aligned}
$$

where $\rho_{\mathrm{H}}$ and $\rho_{\mathrm{L}}$ are hydrate and liquid densities, $\psi_{\mathrm{h}}$ and $\psi_{\max }$ are hydrate volume fraction and its maximum value, $d_{\mathrm{p}}$ is hydrate particle diameter, $D_{\mathrm{SL}}$ is wetted perimeter diameter of hydrate slurry phase, and $\varepsilon_{\mathrm{f}}$ is the absolute roughness of the pipe wall.

Substituting (7a) and (7b) into (6c), (10) can be obtained.

$$
\begin{aligned}
F= & \pm f_{\mathrm{SL}} \frac{\rho_{\mathrm{SL}} U_{\mathrm{SL}}^{2}}{2} \frac{S_{\mathrm{SL}}}{A R_{\mathrm{SL}}}-f_{\mathrm{G}} \frac{\rho_{\mathrm{G}} U_{\mathrm{G}}^{2}}{2} \frac{S_{\mathrm{G}}}{A R_{\mathrm{G}}} \\
& \mp f_{\mathrm{I}} \frac{\rho_{\mathrm{f}}\left(U_{\mathrm{G}}-U_{\mathrm{SL}}\right)^{2}}{2} S_{\mathrm{I}}\left(\frac{1}{A R_{\mathrm{G}}}+\frac{1}{A R_{\mathrm{SL}}}\right) \\
& +\left(\rho_{\mathrm{SL}}-\rho_{\mathrm{G}}\right) g \sin \beta,
\end{aligned}
$$

where the first term is positive when $U_{\mathrm{SL}}>0$ and third term is negative when $U_{\mathrm{G}}-U_{\mathrm{SL}}>0$, and vice versa [35]. 


\subsection{Stability Analysis}

2.2.1. Flow Stability Equation. Referring to the method used in interface stability analysis, where the steady-state contribution and perturbation contribution are separated, $U_{\mathrm{SL}}, U_{\mathrm{G}}$, and $h_{\mathrm{SL}}$ can be rewritten as combinations of steady-state part and perturbed part shown in

$$
\begin{aligned}
U_{\mathrm{SL}} & =\bar{U}_{\mathrm{SL}}+\widehat{U}_{\mathrm{SL}}, \\
U_{\mathrm{G}} & =\bar{U}_{\mathrm{G}}+\widehat{U}_{\mathrm{G}}, \\
h_{\mathrm{SL}} & =\bar{h}_{\mathrm{SL}}+\widehat{h}_{\mathrm{SL}}, \\
\frac{\partial \bar{U}_{\mathrm{SL}}}{\partial x} & =\frac{\partial \bar{U}_{\mathrm{G}}}{\partial x}=\frac{\partial \bar{h}_{\mathrm{SL}}}{\partial x}=0, \\
\widehat{U}_{\mathrm{SL}} & \ll 1, \\
\bar{U}_{\mathrm{SL}} & \widehat{U}_{\mathrm{G}} \\
\frac{\bar{U}_{\mathrm{G}}}{} & \ll 1, \\
\widehat{h}_{\mathrm{SL}} & \ll 1 . \\
\bar{h}_{\mathrm{SL}} &
\end{aligned}
$$

Based on (11a), (11b), and (11c), continuous equations (2a) and (2b) and momentum equations (6a), (6b), and (6c) can be linearized and simplified. The following fifth-order linear equation can be obtained to describe one-dimensional steady-state gas-hydrate slurry stratified flow.

$$
\begin{aligned}
\sigma & \frac{A}{A_{\mathrm{SL}}^{\prime}} \frac{\partial^{5} \widehat{h}_{\mathrm{SL}}}{\partial x^{5}}+2\left[\frac{\bar{\rho}_{\mathrm{G}} \bar{U}_{\mathrm{G}}}{R_{\mathrm{G}}}+\frac{\bar{\rho}_{\mathrm{SL}} \bar{U}_{\mathrm{SL}}}{R_{\mathrm{SL}}}\right] \frac{\partial^{3} \widehat{h}_{\mathrm{SL}}}{\partial t \partial x^{2}} \\
+ & {\left[\frac{\bar{\rho}_{\mathrm{G}} \bar{U}_{\mathrm{G}}^{2}}{R_{\mathrm{G}}}+\frac{\bar{\rho}_{\mathrm{SL}} \bar{U}_{\mathrm{SL}}^{2}}{R_{\mathrm{SL}}}+\Pi \frac{A}{A_{\mathrm{SL}}^{\prime}}\right] \frac{\partial^{3} \widehat{h}_{\mathrm{SL}}}{\partial x^{3}} } \\
+ & {\left[\frac{\bar{\rho}_{\mathrm{G}}}{R_{\mathrm{G}}}+\frac{\bar{\rho}_{\mathrm{SL}}}{R_{\mathrm{SL}}}\right] \frac{\partial^{3} \widehat{h}_{\mathrm{SL}}}{\partial t^{2} \partial x}-\left[\frac{\Gamma_{\mathrm{G}}}{R_{\mathrm{G}}}\left(\frac{1}{R_{\mathrm{SL}}}+\frac{1}{R_{\mathrm{G}}}\right)\right.} \\
& \left.-\frac{1}{R_{\mathrm{SL}}}\left(\frac{\partial F}{\partial \bar{U}_{\mathrm{SL}}}\right)_{h_{\mathrm{SL}}, U_{\mathrm{G}}}+\frac{1}{R_{\mathrm{G}}}\left(\frac{\partial F}{\partial \bar{U}_{\mathrm{G}}}\right)_{h_{\mathrm{SL}}, U_{\mathrm{SL}}}\right] \frac{\partial^{2} \widehat{h}_{\mathrm{SL}}}{\partial t \partial x} \\
& -\left[\frac{\Gamma_{\mathrm{G}} \bar{U}_{\mathrm{G}}}{R_{\mathrm{G}}}\left(\frac{1}{R_{\mathrm{SL}}}+\frac{1}{R_{\mathrm{G}}}\right)+\frac{A}{A_{\mathrm{SL}}^{\prime}}\left(\frac{\partial F}{\partial \bar{h}_{L}}\right)_{U_{\mathrm{SL}}, U_{\mathrm{G}}}\right. \\
& \left.-\frac{\bar{U}_{\mathrm{SL}}}{R_{\mathrm{SL}}}\left(\frac{\partial F}{\partial \bar{U}_{\mathrm{SL}}}\right)_{h_{\mathrm{SL}}, U_{\mathrm{G}}}+\frac{\bar{U}_{\mathrm{G}}}{R_{\mathrm{G}}}\left(\frac{\partial F}{\partial \bar{U}_{\mathrm{G}}}\right)_{h_{\mathrm{SL}}, U_{\mathrm{SL}}}\right] \frac{\partial x^{2}}{} \\
= & 0 .
\end{aligned}
$$

Characterize the perturbation of liquid hold-up in exponential form as in the following [36]:

$$
\widehat{h}_{\mathrm{SL}}=\varepsilon e^{i(w t-k x)},
$$

where $w, k$, and $\varepsilon$ are parameters in wave equation.

Substituting (13) into (12), (14a), (14b), (14c), (14d), (14e), (14f), (14g), (14h), (14i), and (14j) can be obtained to describe the stratified smooth flow stability of gas-hydrate slurry stratified flow.

$$
w^{2}-2\left(a^{*} k-i b^{*}\right) w-d^{*} k^{4}+c^{*} k^{2}-i e^{*} k=0,
$$

where following parameters are defined to simplify expression (14a):

$$
\begin{aligned}
& a^{*}=\frac{1}{\rho^{*}}\left[\frac{\bar{\rho}_{\mathrm{G}} \bar{U}_{\mathrm{G}}}{R_{\mathrm{G}}}+\frac{\bar{\rho}_{\mathrm{SL}} \bar{U}_{\mathrm{SL}}}{R_{\mathrm{SL}}}\right] \text {, } \\
& b^{*}=\frac{1}{2 \rho^{*}}\left[\frac{\Gamma}{R_{\mathrm{G}}}\left(\frac{1}{R_{\mathrm{SL}}}+\frac{1}{R_{\mathrm{G}}}\right)-\left(\frac{\partial F}{\partial \bar{U}_{\mathrm{SL}, \mathrm{S}}}\right)_{R_{\mathrm{SL}}, U_{\mathrm{G}, \mathrm{S}}}\right. \\
& \left.+\left(\frac{\partial F}{\partial \bar{U}_{\mathrm{G}, \mathrm{S}}}\right)_{R_{\mathrm{SL}}, U_{\mathrm{SL}, \mathrm{S}}}\right] \\
& c^{*}=\frac{1}{\rho^{*}}\left\{\frac{\bar{\rho}_{\mathrm{G}} \bar{U}_{\mathrm{G}}{ }^{2}}{R_{\mathrm{G}}}+\frac{\bar{\rho}_{\mathrm{SL}} \bar{U}_{\mathrm{SL}}{ }^{2}}{R_{\mathrm{SL}}}\right. \\
& +\frac{1}{A_{\mathrm{SL}}^{\prime}}\left[\rho_{\mathrm{f}}\left(U_{\mathrm{G}}-U_{\mathrm{SL}}\right)^{2} C_{h} S_{\mathrm{I}}\left(\frac{1}{R_{\mathrm{G}}}+\frac{1}{R_{\mathrm{SL}}}\right)\right. \\
& \left.\left.-A\left(\rho_{\mathrm{SL}}-\rho_{\mathrm{G}}\right) g \cos \beta\right]\right\} \text {, } \\
& d^{*}=\frac{\sigma}{\rho^{*}} \frac{A}{A_{\mathrm{SL}}^{\prime}} \\
& e^{*}=\frac{1}{\rho^{*}}\left[\frac{\Gamma_{\mathrm{G}} \bar{U}_{\mathrm{G}}}{R_{\mathrm{G}}}\left(\frac{1}{R_{\mathrm{SL}}}+\frac{1}{R_{\mathrm{G}}}\right)+\left(\frac{\partial F}{\partial \bar{R}_{\mathrm{L}}}\right)_{U_{\mathrm{SL}}, U_{\mathrm{G}}}\right] \text {, } \\
& \rho^{*}=\frac{\bar{\rho}_{\mathrm{G}}}{R_{\mathrm{G}}}+\frac{\bar{\rho}_{\mathrm{SL}}}{R_{\mathrm{SL}}}, \\
& \left(\frac{\partial F}{\partial \bar{U}_{\mathrm{SL}, \mathrm{S}}}\right)_{R_{\mathrm{SL}}, U_{\mathrm{G}, \mathrm{S}}}=\frac{1}{R_{\mathrm{SL}}}\left(\frac{\partial F}{\partial \bar{U}_{\mathrm{SL}}}\right)_{h_{\mathrm{SL}}, U_{\mathrm{G}}}, \\
& \left(\frac{\partial F}{\partial \bar{U}_{\mathrm{G}, \mathrm{S}}}\right)_{R_{\mathrm{SL}}, U_{\mathrm{SL}, \mathrm{S}}}=\frac{1}{R_{\mathrm{G}}}\left(\frac{\partial F}{\partial \bar{U}_{\mathrm{G}}}\right)_{h_{\mathrm{SL}}, U_{\mathrm{SL}}}, \\
& \left(\frac{\partial F}{\partial \bar{R}_{\mathrm{SL}}}\right)_{U_{\mathrm{SL}, \mathrm{S}}, U_{\mathrm{G}, \mathrm{S}}}=\frac{A}{A_{\mathrm{SL}}^{\prime}}\left(\frac{\partial F}{\partial \bar{h}_{L}}\right)_{U_{\mathrm{SL}}, U_{\mathrm{G}}} \\
& -\frac{\bar{U}_{\mathrm{SL}}}{R_{\mathrm{SL}}}\left(\frac{\partial F}{\partial \bar{U}_{\mathrm{SL}}}\right)_{h_{\mathrm{SL}}, U_{\mathrm{G}}}+\frac{\bar{U}_{\mathrm{G}}}{R_{\mathrm{G}}}\left(\frac{\partial F}{\partial \bar{U}_{\mathrm{G}}}\right)_{h_{\mathrm{SL}}, U_{\mathrm{SL}}} .
\end{aligned}
$$


2.2.2. Stability Criterion. Analytically solve quadratic equations (14a), (14b), (14c), (14d), (14e), (14f), (14g), (14h), (14i), and $(14 \mathrm{j})$, and roots can be expressed as follows:

$$
\begin{aligned}
w & =\left(a^{*} k-i b^{*}\right) \\
& \pm \sqrt{\left(a^{* 2}-c^{*}\right) k^{2}-b^{* 2}+d^{*} k^{4}+i\left(e^{*} k-2 a^{*} b^{*} k\right)} .
\end{aligned}
$$

Substituting $w=w_{\mathrm{R}}+w_{\mathrm{I}}$, (14a) can be split into imaginary part and real part as follows:

Imaginary part:

$$
-2 a^{*} k w_{\mathrm{I}}+2 b^{*} w_{\mathrm{R}}-e^{*} k+2 w_{\mathrm{R}} w_{\mathrm{I}}=0
$$

$$
\begin{aligned}
& \text { Real part: } \\
& w_{\mathrm{R}}^{2}-2 a^{*} k w_{\mathrm{R}}-d^{*} k^{4}+c^{*} k^{2}-2 b^{*} w_{\mathrm{I}}-w_{\mathrm{I}}^{2}=0
\end{aligned}
$$

It could be found in (16a) and (16b) that if $w_{\mathrm{I}}<0$, perturbation contribution of liquid holdup increases exponentially with time, resulting in flow instability. With $w_{\mathrm{I}}$ approaching zero, stability criterion for gas-hydrate slurry stratified smooth flow can be derived as follows:

$$
\left(\frac{e^{*}}{2 b^{*}}-a^{*}\right)^{2}-\left(a^{* 2}-c^{*}\right)-d^{*} k^{2}<0 .
$$

Analyzing (17), two critical wave velocities at the inception of instability are introduced as (18a) and (18b). $C_{\mathrm{V}}$ is the critical wave velocity considering the viscous effect, while $C_{I V}$ is the one without the influence of viscosity $[33,37,38]$.

$$
\begin{aligned}
C_{\mathrm{V}}=\frac{w_{\mathrm{R}}}{k}=\frac{e^{*}}{2 b^{*}}=\frac{\left(\Gamma \bar{U}_{\mathrm{G}} / R_{\mathrm{G}}\right)\left(1 / R_{\mathrm{SL}}+1 / R_{\mathrm{G}}\right)+\left(\partial F / \partial \bar{R}_{\mathrm{L}}\right)_{\mathrm{U}_{\mathrm{SL}} U_{\mathrm{G}}}}{\left(\Gamma / R_{\mathrm{G}}\right)\left(1 / R_{\mathrm{SL}}+1 / R_{\mathrm{G}}\right)-\left(\partial F / \partial \bar{U}_{\mathrm{SL}, \mathrm{S}}\right)_{R_{\mathrm{SL}}, U_{\mathrm{G}, \mathrm{S}}}+\left(\partial F / \partial \overline{\mathrm{U}}_{\mathrm{G}, \mathrm{S}}\right)_{R_{\mathrm{SL}}, U_{\mathrm{SL}, \mathrm{S}}}} \\
C_{\mathrm{IV}}=a^{*}=\frac{\bar{\rho}_{\mathrm{G}} \bar{U}_{\mathrm{G}} R_{\mathrm{SL}}+\bar{\rho}_{\mathrm{SL}} \bar{U}_{\mathrm{SL}} R_{\mathrm{G}}}{\bar{\rho}_{\mathrm{G}} R_{\mathrm{SL}}+\bar{\rho}_{\mathrm{SL}} R_{\mathrm{G}}}
\end{aligned}
$$

Substituting (14a), (14b), (14c), (14d), (14e), (14f), (14g), (14h), (14i), and (14j) and (18a) and (18b) into (17), the stability criterion for gas-hydrate slurry stratified smooth flow can be obtained as follows:

$$
\begin{gathered}
\left(C_{\mathrm{V}}-C_{\mathrm{IV}}\right)^{2}+\frac{\bar{\rho}_{\mathrm{G}} \bar{\rho}_{\mathrm{SL}}}{\rho^{* 2} R_{\mathrm{G}} R_{\mathrm{SL}}}\left(\bar{U}_{\mathrm{G}}-\bar{U}_{\mathrm{SL}}\right)^{2} \\
-\frac{\bar{\rho}_{\mathrm{SL}}-\bar{\rho}_{\mathrm{G}}}{\rho^{*}} g \cos \beta \frac{A}{S_{\mathrm{I}}}-\frac{\sigma}{\rho^{*}} \frac{A}{S_{\mathrm{I}}} k^{2} \\
+\frac{\rho_{\mathrm{f}}\left(U_{\mathrm{G}}-U_{\mathrm{SL}}\right)^{2} C_{h}}{\rho^{*}}\left(\frac{1}{R_{\mathrm{G}}}+\frac{1}{R_{\mathrm{SL}}}\right)<0 .
\end{gathered}
$$

In (19), the first term corresponds to the viscous shear stress that amplifies any disturbance on the surface; the second and third terms are stability criterion disregarding viscous effects, also known as the one-dimensional interface IKH instability criterion; the fourth term stands for the surface tension contribution and depends mainly on wave variable $k$; the last term amplifies instability brought by other factors and is independent of the direction of relative velocity as well as shear stress between the two phases.

Neglecting interfacial tension, viscous shear stress, and interface shear stress, (20) can be simplified.

$$
\begin{aligned}
& \left(\bar{U}_{\mathrm{G}}-\bar{U}_{\mathrm{SL}}\right) \\
& \quad<\left(\frac{\bar{\rho}_{\mathrm{G}} R_{\mathrm{SL}}+\bar{\rho}_{\mathrm{SL}} R_{\mathrm{G}}}{\bar{\rho}_{\mathrm{SL}}} \frac{\bar{\rho}_{\mathrm{L}}-\bar{\rho}_{\mathrm{G}}}{\bar{\rho}_{\mathrm{G}}} g \cos \beta \frac{A}{S_{\mathrm{I}}}\right)^{0.5} .
\end{aligned}
$$

Considering the large density difference between gas and hydrate slurry phases, (20) can be further simplified as follows, shown in (21). This equation matches the criterion presented by Taitel and Dukler [14] in 1976.

$$
\left(\bar{U}_{\mathrm{G}}-\bar{U}_{\mathrm{SL}}\right)<\left(\frac{\bar{\rho}_{\mathrm{L}}-\bar{\rho}_{\mathrm{G}}}{\bar{\rho}_{\mathrm{G}}} g \cos \beta \frac{A_{\mathrm{G}}}{S_{\mathrm{I}}}\right)^{0.5} .
$$

Calculation procedure based on the criterion is presented in Scheme 1. For stratified flow boundary determination, superficial velocity of one phase can be calculated when that of the other phase is given. In implanting this model, bisection method is applied in the iteration calculation. Scheme 1 shows the flowchart to calculate liquid superficial velocity $U_{\mathrm{SL}, \mathrm{S}}$ at a given gas superficial velocity $U_{\mathrm{G}, \mathrm{S}}$, while $U_{\mathrm{G}, \mathrm{S}}$ at given $U_{\mathrm{SL}, \mathrm{S}}$ can be obtained through similar procedure.

\section{Experiments}

To analyze stability transition criterion for stratified smooth flow using (19), parameters including $\xi_{\mathrm{I}}, \eta_{\mathrm{I}}, C_{h}$, and $k$ need to be determined. In this paper, these parameters were obtained based on the experiments at different water cuts using highpressure hydrates slurry flow loop.

3.1. Material and Facility. A double-pass high-pressure horizontal flow loop shown in Figure 2 was designed and established in China University of Petroleum, Beijing, supported by CNOOC [24, 39-42]. This flow loop is $30 \mathrm{~m}$ long, with inner diameter of 1 inch and pressure exceeding $10 \mathrm{MPa}$. Test section temperature can be maintained from 


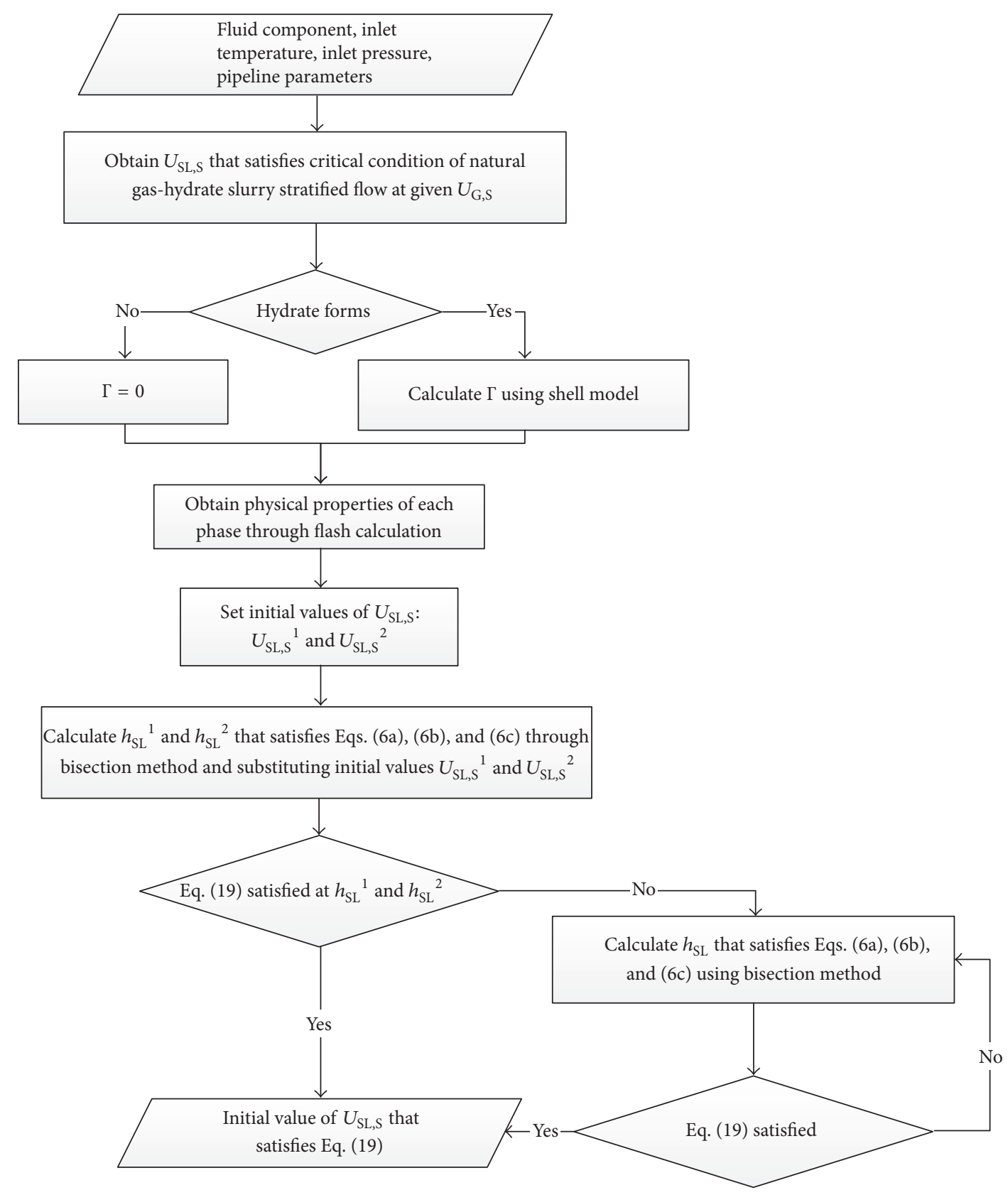

SCHEME 1: Algorithm to determine the stratified flow boundary by calculating liquid superficial velocity $U_{\mathrm{SL}, \mathrm{S}}$ at a given gas superficial velocity $U_{\mathrm{G}, \mathrm{S}}$.

$-20^{\circ} \mathrm{C}$ to $80^{\circ} \mathrm{C}$ by circulating water-glycol blend with the countercurrent flowing surrounding it in a 2 -inch jacket. Fluid inside the loop can be observed through high-pressure windows at two different locations. Gas and liquid can be injected separately by a plunge compressor $\left(2200 \mathrm{~m}^{3} / \mathrm{h}\right)$ and a magnetic centrifugal pump $\left(12.0 \mathrm{~m}^{3} / \mathrm{h}\right)$. Gas is injected at the inlet of the test section. At the outlet of the test section, gas and liquid flow into an insulated separator and are redirected towards the test section after pressurization.

Thermocouples are placed along the pipe, inside the separator, inside the water-glycol system, and on different gas utilities. A Coriolis flow meter is stalled to measure liquid mixture density and flow rate. Two FM1000 gamma ray densitometers are available to measure the mean density of the multiphase fluid. Differential pressure sensors are installed to follow the evolution of pressure. Rapid data acquisition system permits the detection of quickly occurring events. A Focused Beam Reflectance Measurements (FBRM) probe and Particle Video Microscope (PVM) are installed to capture the evolution of the droplets, bubbles, or solid particles in fluid.

Deionized water, civil natural gas, and -20\# diesel (compositions listed in Table 1) were used for the experiments. The dosage of added antiagglomerate was $3 \mathrm{wt} \%$ (measuring error $\pm 0.01 \mathrm{~g}$ ) to prevent the hydrate crystals from aggregating [43]. 


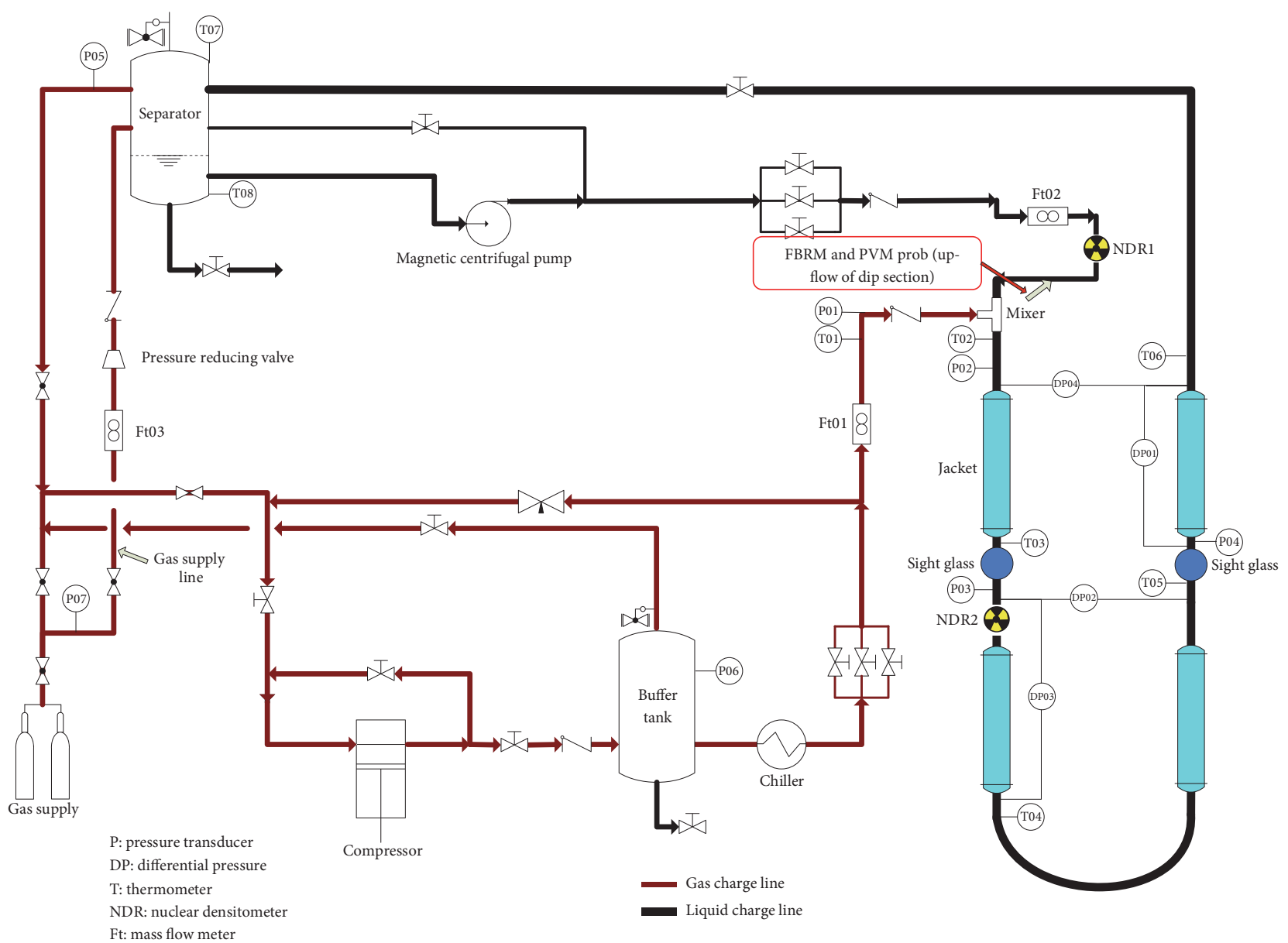

FIGURE 2: Sketch of high-pressure hydrate flow loop.

3.2. Experiment Procedure. Four groups of experiments at different water cuts $(15 \%, 20 \%, 25 \%$, and $30 \%)$ were carried out with gas, $-20 \#$ diesel oil, and deionized water. Experimental conditions are listed in Table 2. Specific experimental procedure is detailed as follows:

(1) Vacuum the experimental system one hour before injecting the required amount of $-20 \#$ diesel oil, deionized water, and antiagglomerates.

(2) Start and set the temperature controller at $18^{\circ} \mathrm{C}$, the magnetic centrifugal pump at $40 \mathrm{~Hz}$, and the control valve at $100 \%$, get the liquid phase well circulated for least 5 hours to form water-in-oil emulation, and then open FBRM to monitor changes of the particles in the fluid.

(3) Open the gas injection valve and pressure the system up to experimental set point, after the temperature of the system stays constant at $18^{\circ} \mathrm{C}$ and particles size observed using FBRM becomes stable.

(4) Set the system temperature to experimental set point and cool the flow loop; hydrate would form as the temperature drops below the hydrate equilibrium temperate at the system pressure.
(5) Maintain temperature and pressure at experimental set point for at least 5 hours to ensure the fully hydrate formation, adjust compressor inlet valve and pump speed to attain a gas flow rate within $20 \sim 195 \mathrm{~kg} / \mathrm{h}$ and liquid flow rate within $75 \sim 860 \mathrm{~kg} / \mathrm{h}$, and then observe the flow pattern and record the data; for each data point presented in this work, flow rate of both gas and slurry phase were controlled and flow pattern was observed when the flow rates, pressure, and temperature were stabilized.

(6) Increase the system temperature, stop the compressor and pump, evacuate the residual gas, discharge the experiment liquid, clean and flush the flow loop with compressed air, and replace it with nitrogen.

(7) Repeat the procedure at different water cuts.

\section{Results and Discussions}

4.1. Experiment Results. In the experiments, 293 smooth and nonsmooth stratified flow pattern data points at different water cuts were obtained under steady-state conditions (Tables S.1-S.4), which was visually observed through the sight glass of the loop. Four types of flow patterns were found, 
TABLE 1: Compositions of civil natural gas and -20\# diesel oil.

\begin{tabular}{lcc}
\hline Comp & Mol\% \\
\hline $\mathrm{N}_{2}$ & Civil natural gas \\
$\mathrm{CO}$ & 1.5603 \\
$\mathrm{CO}_{2}$ & 2.0911 \\
$\mathrm{C}_{1}$ & 0.9129 \\
$\mathrm{C}_{2}$ & 90.6061 \\
$\mathrm{C}_{3}$ & 3.1207 \\
$\mathrm{iC}_{4}$ & 3.1207 \\
$\mathrm{iC}_{5}$ & 0.3291 \\
$\mathrm{nC}_{6}+$ & 0.0425 \\
& & 0.0106 \\
$\mathrm{C}_{11}$ & \\
$\mathrm{C}_{12}$ & 0.8863 \\
$\mathrm{C}_{13}$ & 3.3586 \\
$\mathrm{C}_{14}$ & 5.3886 \\
$\mathrm{C}_{15}$ & 6.1990 \\
$\mathrm{C}_{16}$ & 6.7780 \\
$\mathrm{C}_{17}$ & 6.8310 \\
$\mathrm{C}_{18}$ & 7.9890 \\
$\mathrm{C}_{19}$ & 7.4618 \\
$\mathrm{C}_{20}+$ & 6.3752 \\
& & 48.7325 \\
\hline
\end{tabular}

TABLE 2: Experimental conditions of gas-hydrate slurry flow.

\begin{tabular}{lcccc}
\hline $\begin{array}{l}\text { Water cut } \\
(\%)\end{array}$ & $\begin{array}{c}P \\
(\mathrm{MPa})\end{array}$ & $\begin{array}{c}T \\
(\mathrm{~K})\end{array}$ & $\begin{array}{c}V_{\mathrm{L}} \\
\left(\mathrm{m}^{3}\right)\end{array}$ & $\begin{array}{c}N_{\text {exp }}{ }^{*} \\
(-)\end{array}$ \\
\hline 15 & 4.13 & 277.33 & 0.0777 & 34 \\
20 & 4.26 & 279.82 & 0.0875 & 75 \\
25 & 3.85 & 278.99 & 0.0933 & 96 \\
30 & 4.20 & 278.99 & 0.1000 & 88 \\
\hline
\end{tabular}

${ }^{*} N_{\text {exp }}$ : number of experimental data points.

including two typical flow patterns (stratified smooth flow and slug flow) and two transitional flow patterns (stratified wavy flow and short slug flow). Distinct gas-liquid interface can be observed, and the interface was flat for the stratified smooth flow (Figure 3(a)) and was wavy for stratified wave flow (Figure 3(b)). A liquid film zone and a liquid slug were found intermittently for slug flow (Figure 4), while a relatively longer liquid film and shorter slug length were found for short slug flow.

The morphologies, sizes, and distributions of fully formed hydrate particles in the slurry were recorded by PVM as shown in Figure 5. The chord length distribution before and after hydrates formation is displayed in Figure 6. According to experimental observations, it is can be concluded that hydrates particles form as shells covering water droplets in the water-in-oil emulsion, and the size of hydrates particles will be enlarged compared with water droplet. In addition, hydrate particle morphologies, sizes, and distributions showed no distinguishable difference at different flow patterns, implying that their influences on flow pattern transition were not signification.

4.2. Model Implementation. Based on experimental conditions listed in Table 2, hydrate growth parameters and gas consumption rate at different water cuts were calculated using the inward and outward hydrate growth shell model [23]. Results presented in Table 3 showed that gas consumption rate increased with water cut. Detailed calculation procedure including water consumption and hydrate fraction is presented in the supporting information (Hydrate Growth Model Implementation). Gas-slurry stratified smooth flow region transition boundary at different water cuts was obtained by implementing the calculation procedure presented in Scheme 1. Parameters in the model are obtained, where $\xi_{\mathrm{I}}$ is $0.01, \eta_{\mathrm{I}}$ is $-0.2, C_{h}$ is 0.01 , and $k$ is 10 .

4.3. Model Evaluation. To compare the transition criterion of smooth stratified flow to other flow patterns for gashydrate slurry flow developed in this work with the classical flow pattern distribution models, flow region boundaries calculated using this model as well as that calculated using Taitel-Dukler [14] and Mandhane [13] methods are presented in Figure 7.

As is shown in Figure 7, Mandhane's model can roughly divide stratified flow from nonstratified flow at four water cuts, yet the results lead to a larger smooth stratified flow region. Taitel-Dukler model cannot give a satisfying stratified flow transition boundary, due to not considering the effect of hydrate formation on flow stability. Transition boundaries obtained based on the model developed in this work show good agreement with experimental data.

All data points are summarized in Figure 8. It can be seen that no distinctive effect of water cut on flow pattern division is observed, though gas consumption rate differs evidently according to Table 3. This may be due to the similar water consumption rates and hydrate fractions as shown in Figure 9. As calculated flow pattern boundary is primarily affected by fluid viscosity, and hydrate slurry viscosity is further determined by hydrate volume fraction, proximal transition lines are obtained under similar hydrate fraction though at different water cuts.

The pattern experiment data of gas-hydrate slurry multiphase flow pattern in this work are not effectively enough to obtain more precise correlation parameters or investigate the flow pattern transition mechanism deeply. More experimental and theoretical research should be carried out in the future. Nevertheless, the good agreement with experimental data proved this work to be both feasible and significant.

\section{Conclusion}

In this work, a one-dimension two-fluid model for gashydrate slurry stratified flow was developed based on perturbation method, and a stability criterion for smooth stratified flow was proposed. In establishing the criterion, mass transfer between gas and slurry phase caused by hydrate formation 
TABLE 3: Hydrate growth parameters of different water cuts and gas consumed rate.

\begin{tabular}{lcccccc}
\hline $\begin{array}{l}\text { Water cut } \\
\%\end{array}$ & $\begin{array}{c}K^{*} \times 10^{-7} \\
\mathrm{~mol} /\left(\mathrm{m}^{2} \cdot \mathrm{Mpa} \cdot \mathrm{s}\right)\end{array}$ & $\begin{array}{c}D_{\mathrm{f}}{ }^{0} \times 10^{-9} \\
\mathrm{~m}^{2} / \mathrm{s}\end{array}$ & $\xi$ & $\begin{array}{c}\varepsilon_{\mathrm{H}}{ }^{0} \times 10^{-32} \\
\mathrm{~m}^{3}\end{array}$ & $\begin{array}{c}\Gamma_{G} \times 10^{-4} \\
\mathrm{~kg} / \mathrm{m}^{3} \cdot \mathrm{s}\end{array}$ \\
\hline 15 & 4.364 & 1.149 & 1.489 & 14.66 & 0.2527 & 7.188 \\
20 & 7.606 & 13.82 & 1.527 & 6.339 & 0.2679 & 9.575 \\
25 & 8.980 & 30.62 & 1.546 & 4.891 & 0.2767 & 11.72 \\
30 & 16.16 & 321.5 & 1.564 & 2.994 & 0.2820 \\
\hline
\end{tabular}

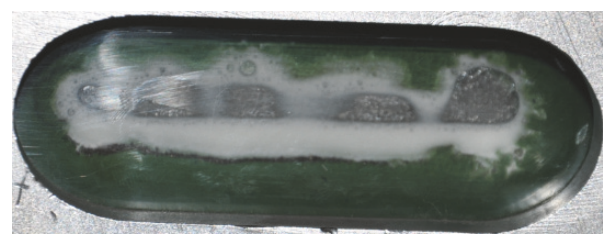

(a)

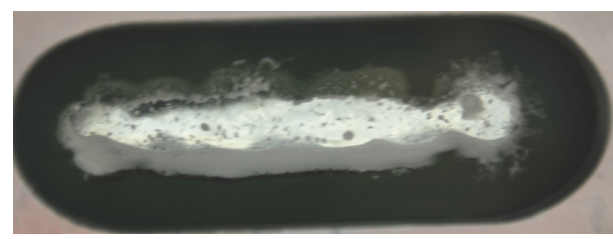

(b)

FIGURE 3: Photos of stratified flow: (a) stratified smooth flow and (b) stratified wave flow.

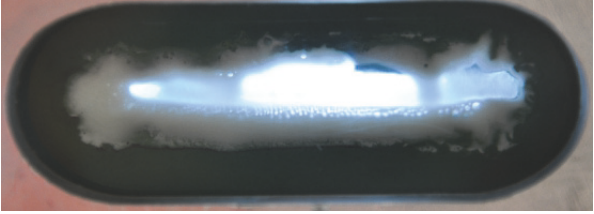

(a)

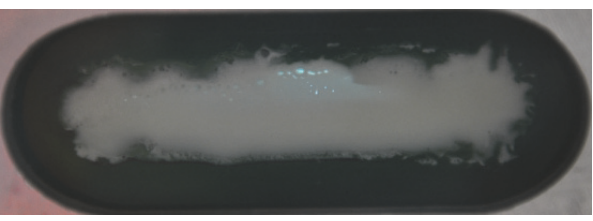

(b)

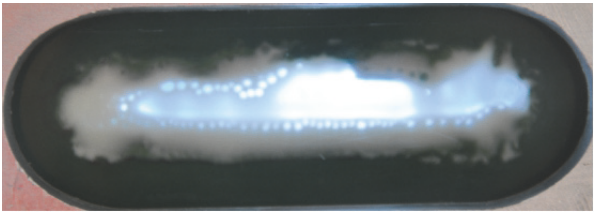

(c)

FIGURE 4: Photos of slug flow: (a) liquid film zone before liquid slug, (b) liquid slug, and (c) liquid film zone after liquid slug.

was considered, and various mathematical techniques were applied in linearizing the equation sets. As the formation of hydrate would evidently complicate the flow, the influences of shear stress, gravity, surface tension, hydrate formation, and other unstable factors were considered. Compared with the classical two-phase gas-liquid stratified flow stability criteria proposed by Taitel-Dukler [14] and Mandhane [13], transition boundary based on this study showed better agreement with experiment results.

Groups of gas-hydrate slurry multiphase flow experiments were carried out on a most advanced high-pressure

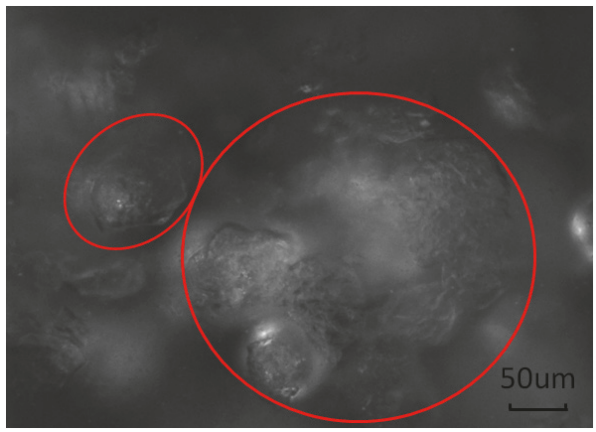

FIGURE 5: Hydrate particles (marked in the red circles) in gas-liquid multiphase system.

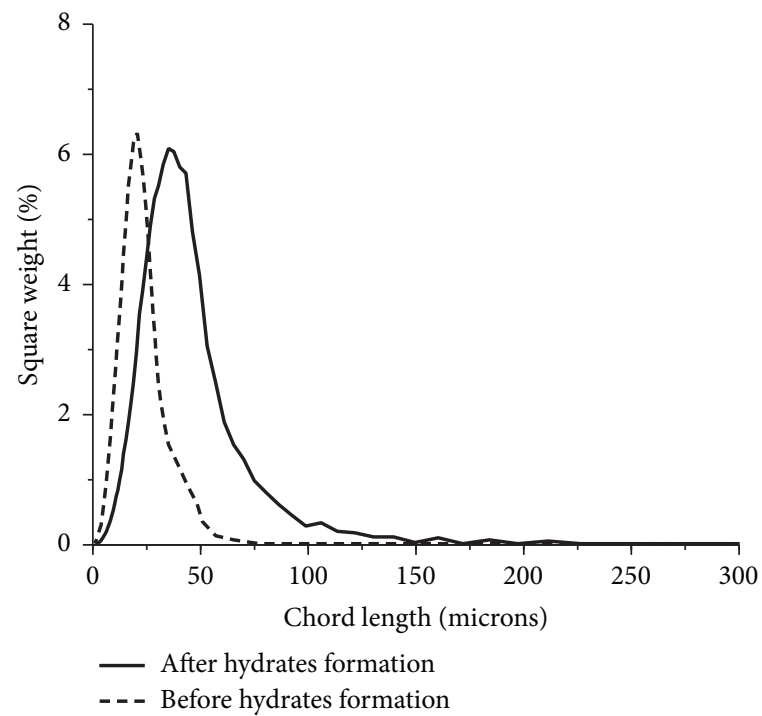

Figure 6: Chord length distribution before and after hydrates formation. 


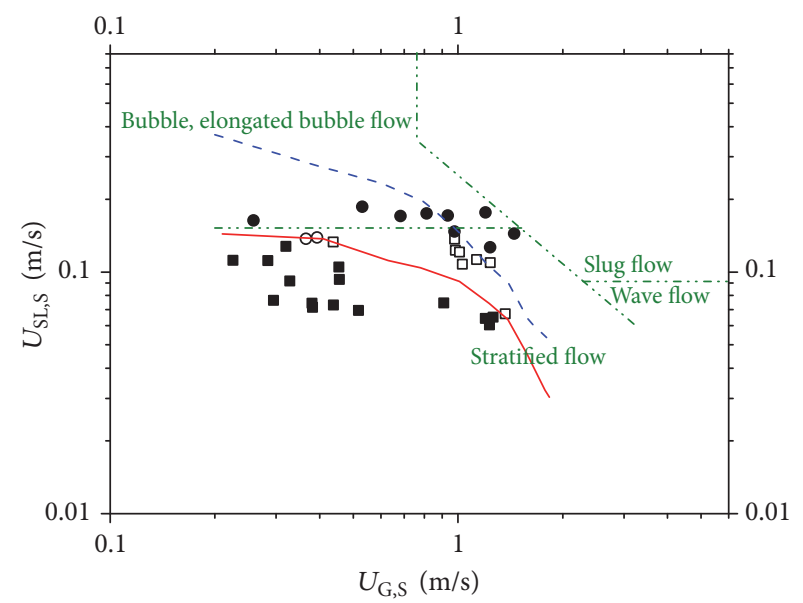

- Stratified smooth flow - - - Mandhane flow pattern map

口 Stratified wave flow - - - Taitel-Dukler model

- Short slug flow

- Slug flow

(a)

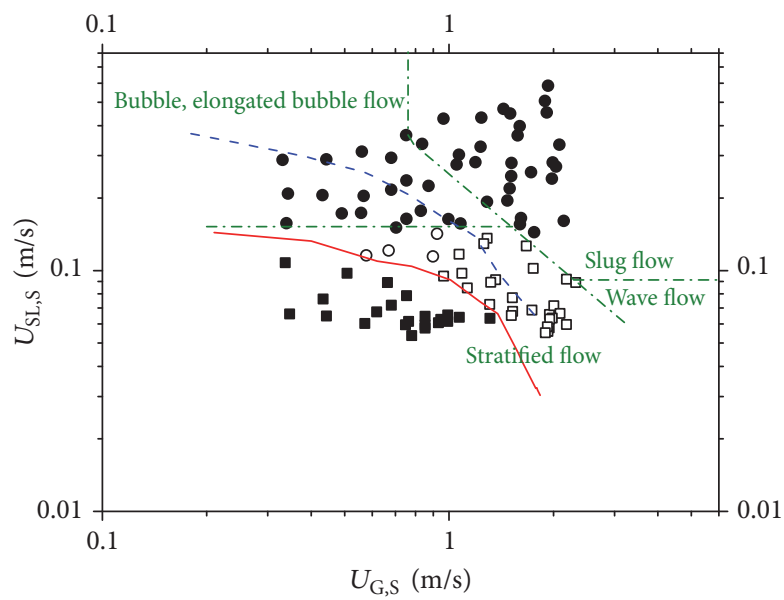

- Stratified smooth flow - - - Mandhane flow pattern map

口 Stratified wave flow _- - Taitel-Dukler model

- Short slug flow _ This model

- Slug flow

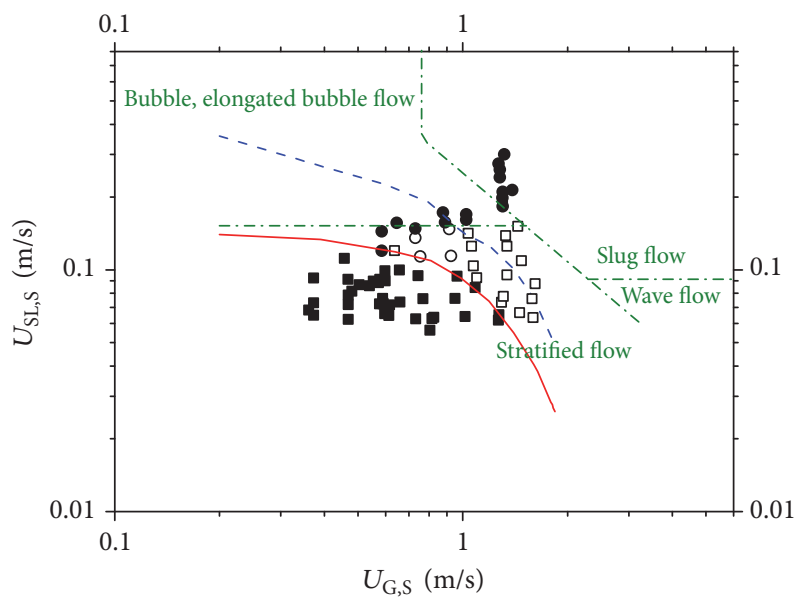

- Stratified smooth flow - - - Mandhane flow pattern map

口 Stratified wave flow --- Taitel-Dukler model

- Short slug flow _ This model

- Slug flow

(b)

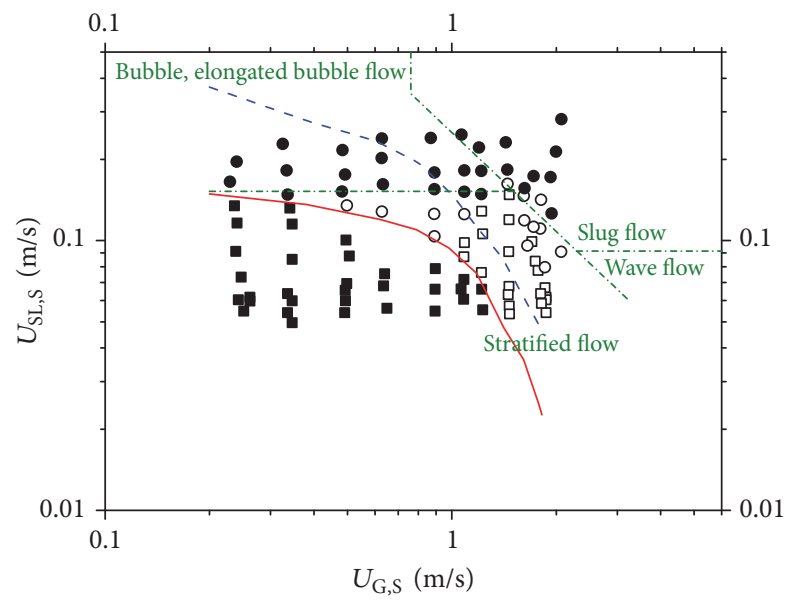

- Stratified smooth flow - -- Taitel-Dukler model

口 Stratified wave flow -..-- Mandhane flow pattern map

o Short slug flow _ This model

- Slug flow

(c)

(d)

FigURE 7: Flow pattern map and boundary for stratified flow of gas-slurry flow at different water cuts: (a) $15 \%$, (b) $20 \%$, (c) $25 \%$, and (d) $30 \%$.

(>10 MPa) hydrate slurry flow loop in China, and 293 experimental data points of both smooth and nonsmooth stratified flow were obtained. Model parameters were generated in combining the experiment data with the gas-hydrate slurry stratified flow stability creation developed in this work, and the model was proved applicable in gas-hydrate slurry multiphase flow numerical simulation and characteristic study.

\section{Nomenclature}

A: Cross area of the pipeline, $\mathrm{m}^{2}$

$A_{\mathrm{G}}$ : Cross area of gas phase, $\mathrm{m}^{2}$

$A_{\mathrm{SL}}$ : Cross area of hydrate slurry phase, $\mathrm{m}^{2}$
$C_{\mathrm{V}}$ : Viscosity critical wave velocity at the inception of instability, $\mathrm{m} \mathrm{s}^{-1}$

$C_{\mathrm{IV}}$ : Nonviscosity critical wave velocity at the inception of instability, $\mathrm{m} \mathrm{s}^{-1}$

$C_{h}$ : Correlated coefficient

$d_{\mathrm{p}}$ : Diameter of hydrates particle, $\mathrm{m}$

$D_{\mathrm{SL}}$ : Diameter of the wetted perimeter of hydrate slurry phase, $m$

$f_{\mathrm{I}}$ : Friction coefficient of interface gas-slurry phase

$f_{\mathrm{G}}$ : Friction coefficient of interface gas phase at pipe wall

$f_{\mathrm{SL}}$ : Friction coefficient of interface slurry at pipe wall

$h_{\mathrm{G}}$ : Height of gas phase, $\mathrm{m}$

$h_{\mathrm{SL}}$ : Height of hydrate slurry phase, $\mathrm{m}$ 


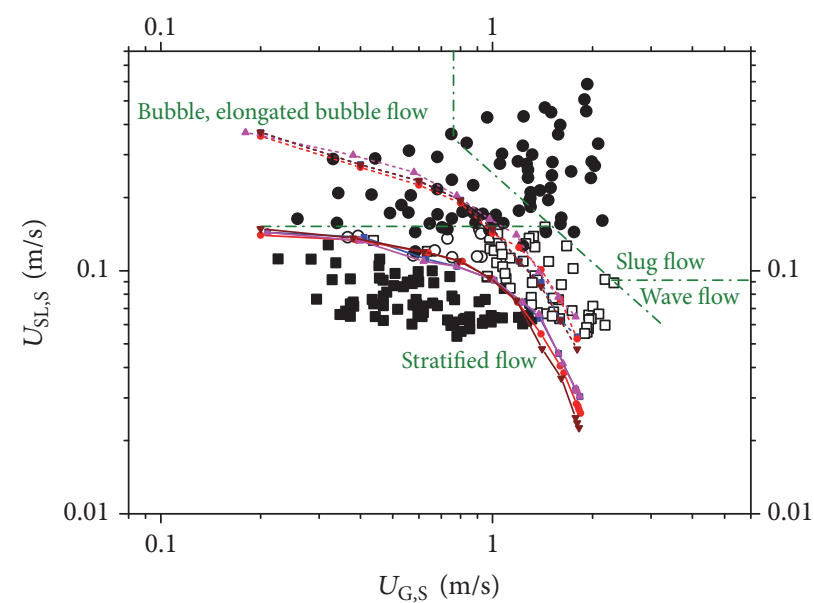

- Stratified smooth flow

- Stratified wave flow

- Short slug flow

- Slug flow

- - Mandhane flow pattern map

- - Taitel-Dukler model, $15 \%$

- Taitel-Dukler model, $20 \%$

FIGURE 8: Flow pattern distribution for gas-slurry stratified flow at different water cuts.

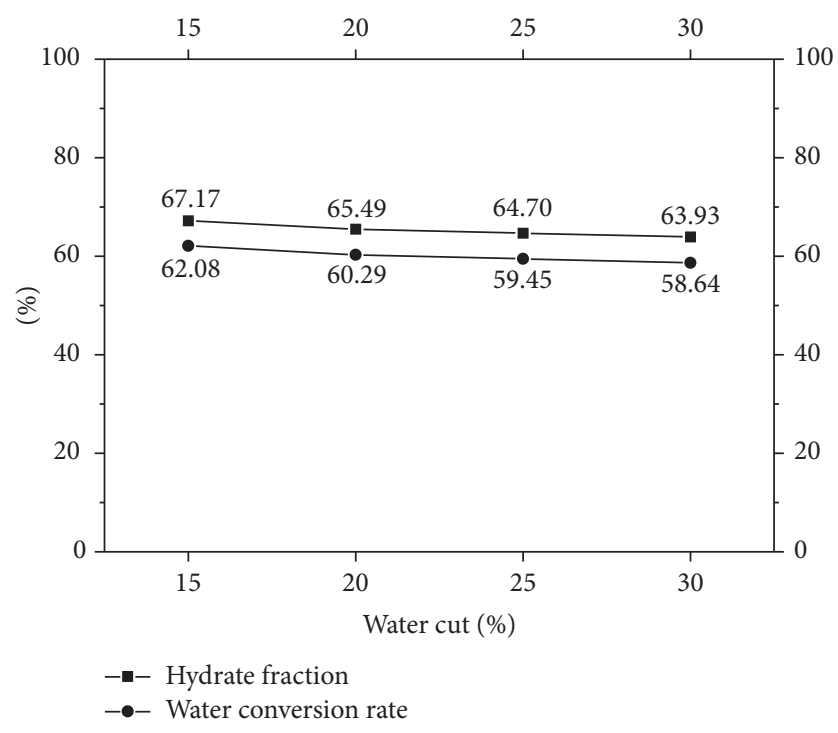

Figure 9: Hydrate fraction and water conversion rate at different water cuts.

$k$ : $\quad$ Parameter in wave equation

$p_{\mathrm{G}}$ : Pressure of gas phase

$p_{\mathrm{SL}}$ : Pressure of hydrate slurry phase

$p_{\mathrm{I}}$ : Pressure at the interface

$p_{\mathrm{IG}}$ : Relative pressure at the interface of gas phase

$p_{\text {ISL }}$ : Relative pressure at the interface of hydrate slurry phase

$R_{\mathrm{G}}$ : Gas phase fraction of pipe cross area

$R_{\mathrm{SL}}$ : Hydrate slurry phase fraction of pipe cross area

$\mathrm{Re}_{\mathrm{G}}$ : Reynolds number of gas phase
$S_{\mathrm{G}}: \quad$ Wetted perimeter of gas phase, $\mathrm{m}$

$S_{\mathrm{I}}$ : Wetted perimeter of interface gas-slurry phase, $m$

$S_{\mathrm{SL}}$ : Wetted perimeter of hydrate slurry phase, $\mathrm{m}$

$t: \quad$ Time, $s$

$U_{\mathrm{G}}:$ Velocity of gas phase, $\mathrm{m} \cdot \mathrm{s}^{-1}$

$U_{\mathrm{SL}}$ : Velocity of hydrate slurry phase, $\mathrm{m} \cdot \mathrm{s}^{-1}$

$w$ : Parameter in wave equation

$x$ : Axial direction of the pipe, $\mathrm{m}$

$\Delta x:$ Distance to the infinitesimal segment, $\mathrm{m}$

$y$ : $\quad$ Radial direction of the pipe, $\mathrm{m}$

$\rho_{\mathrm{H}}$ : Density of hydrates, $\mathrm{kg} / \mathrm{m}^{3}$

$\rho_{\mathrm{L}}: \quad$ Density of oil phase, $\mathrm{kg} / \mathrm{m}^{3}$

$\psi_{\mathrm{h}}$ : Hydrate volume fraction

$\psi_{\max }:$ Maximum hydrate volume fraction

$\Gamma$ : $\quad$ Mass transfer rate between gas phase and hydrate slurry phase, $\mathrm{kg} \cdot \mathrm{s}^{-1} \cdot \mathrm{m}^{-3}$

$\beta$ : $\quad$ Angle of inclination, $\mathrm{rad}$

$\sigma: \quad$ Interfacial tension, $\mathrm{N} / \mathrm{m}$

$\rho_{\mathrm{G}}: \quad$ Density of gas phase, $\mathrm{kg} \cdot \mathrm{m}^{-3}$

$\rho_{\mathrm{SL}}: \quad$ Density of hydrate slurry phase, $\mathrm{kg} \cdot \mathrm{m}^{-3}$

$\rho_{\mathrm{f}}$ : Density of faster phase: subscript $\mathrm{f}$ represents the faster phase, $\mathrm{kg} \cdot \mathrm{m}^{-3}$

$\tau_{\mathrm{G}}:$ Shear friction of interface gas phase at pipe wall, $\mathrm{N}$

$\tau_{\mathrm{I}}$ : Shear friction of interface of gas-slurry phase, $\mathrm{N}$

$\tau_{\mathrm{SL}}$ : Shear friction of interface of slurry at pipe wall, $\mathrm{N}$

$\varepsilon_{\mathrm{f}}: \quad$ Absolute roughness of the pipe wall, $\mathrm{m}$

$\xi_{\mathrm{I}}: \quad$ Friction calculated empirical parameter

$\eta_{\mathrm{I}}$ : $\quad$ Friction calculated empirical parameter

$\varepsilon$ : $\quad$ Parameter in wave equation.

\section{Conflicts of Interest}

The authors declare that they have no conflicts of interest.

\section{Acknowledgments}

This work was supported by the National Natural Science Foundation of China (51306208, 51534007, and 51274218), National Science and Technology Major Project of China (2016ZX05028004-001), National Key Research and Development Plan of China (SQ2016YFSF010222), and Science Foundation of China University of Petroleum-Beijing (2462015YQ0404 and 201602), which are gratefully acknowledged.

\section{References}

[1] E. Dendy Sloan and C. A. Koh, Clathrate Hydrates of Natural Gas, Crc Press, 2008.

[2] E. G. Hammerschmidt, "Formation of gas hydrates in natural gas transmission lines," Industrial \& Engineering Chemistry, vol. 26, no. 8, pp. 851-855, 1934.

[3] D. Sloan et al., Natural Gas Hydrates in Flow Assurance, 2010.

[4] Y. Peysson, "Collision process between particles in the transport of dispersed hydrates in production lines," in Proceedings of the 5th International Conference on Gas Hydrate, Houston, Tex, USA, 2005. 
[5] O. C. Hernandez, Investigation of Hydrate Slurry Flow in Horizontal Pipelines, 2006.

[6] E. Dellecase, G. Geraci, L. Barrios, D. Estanga, R. Domingues, and M. Volk, Hydrate plugging or slurry flow: Effect of key variables, 2008.

[7] J. Gong, B. Shi, and J. Zhao, "Natural gas hydrate shell model in gas-slurry pipeline flow," Journal of Natural Gas Chemistry, vol. 19, no. 3, pp. 261-266, 2010.

[8] J. Gong, B. Shi, and W. Wang, "Numerical study the flow characteristics of gas-hydrate slurry two phase stratified flow," in Proceeding of the 7th International Conference on Multiphase Flow, Tampa, Fla, USA, 2010.

[9] M. Gainville, A. Sinquin, and M. Darbouret, Hydrate Slurry Characterisation for Laminar and Turbulent Flows in Pipelines, 2011.

[10] O. Baker, "Simultaneous flow of oil and gas," Oil \& Gas Journal, vol. 53, p. 185, 1954.

[11] H. Duns and N. C. Ros, Vertical Flow of Gas and Liquid Mixtures in Wells, 1963.

[12] G. W. Govier, K. Aziz, and W. R. Schowalter, The Flow of Complex Mixtures in Pipes, Van Nostrand Reinhold Co., 1972.

[13] J. M. Mandhane, G. A. Gregory, and K. Aziz, "A flow pattern map for gas-liquid flow in horizontal pipes," International Journal of Multiphase Flow, vol. 1, no. 4, pp. 537-553, 1974.

[14] Y. Taitel and A. E. Dukler, "A model for predicting flow regime transitions in horizontal and near horizontal gas-liquid flow," AIChE Journal, vol. 22, no. 1, pp. 47-55, 1976.

[15] Y. Taitel, D. Bornea, and A. E. Dukler, "Modelling flow pattern transitions for steady upward gas-liquid flow in vertical tubes," AIChE Journal, vol. 26, no. 3, pp. 345-354, 1980.

[16] D. Barnea, "A unified model for predicting flow-pattern transitions for the whole range of pipe inclinations," International Journal of Multiphase Flow, vol. 13, no. 1, pp. 1-12, 1987.

[17] A. L. Ballard and E. D. Sloan Jr., "The next generation of hydrate prediction: part III. Gibbs energy minimization formalism," Fluid Phase Equilibria, vol. 218, no. 1, pp. 15-31, 2004.

[18] L. Ballard and E. D. Sloan Jr., "The next generation of hydrate prediction IV: a comparison of available hydrate prediction programs," Fluid Phase Equilibria, vol. 216, no. 2, pp. 257-270, 2004.

[19] G.-J. Chen and T.-M. Guo, "A new approach to gas hydrate modelling," Chemical Engineering Journal, vol. 71, no. 2, pp. 145151, 1998.

[20] P. D. Dholabhai, P. Englezos, and N. Kalogerakis, Kinetics of formation of methane and ethane gas hydrates, 1987.

[21] P. Englezos et al., "Kinetics of gas hydrate formation from mixtures of methane and ethane," Chemical Engineering Science, vol. 42, no. 11, pp. 2659-2666, 1987.

[22] H. C. Kim, P. R. Bishnoi, R. A. Heidemann, and S. S. H. Rizvi, "Kinetics of methane hydrate decomposition," Chemical Engineering Science, vol. 42, no. 7, pp. 1645-1653, 1987.

[23] B.-H. Shi, J. Gong, C.-Y. Sun, J.-K. Zhao, Y. Ding, and G.-J. Chen, "An inward and outward natural gas hydrates growth shell model considering intrinsic kinetics, mass and heat transfer," Chemical Engineering Journal, vol. 171, no. 3, pp. 1308-1316, 2011.

[24] X.-S. Li and Y. Zhang, "Study on dissociation behaviors of methane hydrate in porous media based on experiments and fractional dimension shrinking-core model," Industrial and Engineering Chemistry Research, vol. 50, no. 13, pp. 13-17, 2011.

[25] H. Tajima, A. Yamasaki, and F. Kiyono, "Effects of mixing functions of static mixers on the formation of $\mathrm{CO} 2$ hydrate from the two-phase flow of liquid CO2 and water," Energy and Fuels, vol. 19, no. 6, pp. 2364-2370, 2005.

[26] L. E. Zerpa et al., "Overview of Csmhyk: a Transient Hydrate Formation Model Developed Over a Decade of Hydrate Research," 2011.

[27] S. Joshi, I. Rao, L. Zerpa et al., "Understanding hydrate plug formation from high water cut systems with a four inch flowloop," in Proceedings of the 7th International Conference on Gas Hydrates (ICGH '11), Edinburgh, UK, July 2011.

[28] J. Zhao, "Study on flow properties of hydrate slurry in multiphase pipeline," in Oil and Gas Storage and Transportation, China University of Petroleum, Beijing, China, 2009.

[29] O. Kwon, S. Ryou, and W. Sung, "Numerical modeling study for the analysis of transient flow characteristics of gas, oil, water, and hydrate flow through a pipeline," Korean Journal of Chemical Engineering, vol. 18, no. 1, pp. 88-93, 2001.

[30] L. Ding, B. Shi, X. Lv et al., "Investigation of natural gas hydrate slurry flow properties and flow patterns using a high pressure flow loop," Chemical Engineering Science, vol. 146, pp. 199-206, 2016.

[31] P. Becher, Principles of Colloid and Surface Chemistry, Dekker, 1977.

[32] D. Barnea and Y. Taitel, "Non-linear interfacial instability of separated flow," Chemical Engineering Science, vol. 49, no. 14, pp. 2341-2349, 1994.

[33] N. Brauner and D. M. Maron, "Stability of two-phase stratified flow as controlled by laminar/turbulent transition," International Communications in Heat and Mass Transfer, vol. 21, no. 1, pp. 65-74, 1994.

[34] P. Yannick et al., Flow of Hydrates Dispersed in Production Lines, 2003.

[35] D. Deng, "Simulation study on natural gas-gas condensate flow characteristics in multiphase transportation pipeline," in Oil and Gas Storage and Transportation, China University of Petroleum, Beijing, China, 2005.

[36] P. Drazin and W. Reid, "Hydrodynamic stability," Journal of Fluid Mechanics, vol. 124, 1981.

[37] D. Barnea, "On the effect of viscosity on stability of stratified gas-liquid flow-application to flow pattern transition at various pipe inclinations," Chemical Engineering Science, vol. 46, no. 8, pp. 2123-2131, 1991.

[38] D. Barnea and Y. Taitel, "Kelvin-Helmholtz stability criteria for stratified flow: viscous versus non-viscous (inviscid) approaches," International Journal of Multiphase Flow, vol. 19, no. 4, pp. 639-649, 1993.

[39] W. Li, "Experimental study on multiphase flow mechanism of hydrate slurry in pipes," in Oil and Gas Storage and Transportation Engineering, China University of Petroleum, Beijing, China, 2012.

[40] X. Lv et al., "Experimental study on natural gas hydrate slurry flow," Spe Journal, vol. 2, no. 2, pp. 199-216, 2012.

[41] X. Lv, D. Yu, W. Li, B. Shi, and J. Gong, "Experimental study on blockage of gas hydrate slurry in a flow loop," in Proceeding of the 9th International Pipeline Conference (IPC '12), pp. 37-43, 2012. 
[42] X. Lv, J. Gong, W. Li, Y. Tang, and J. Zhao, "Focused-beam reflectance method aids hydrate blockage prediction," Oil and Gas Journal, vol. 111, no. 1, pp. 99-107, 2013.

[43] C. Y. Sun et al., "The experimental evaluation for controlling hydrate plug in oil-gas-water multiphase pipeline," in Proceeding of the 2nd Chinese National Chemical and Biochemical Engineering Annual Meeting, Beijing, China, 2005. 


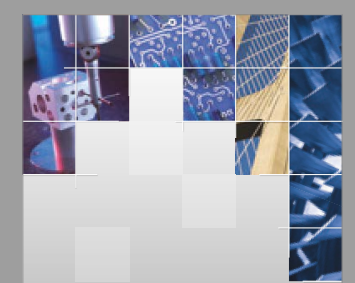

\section{Enfincering}
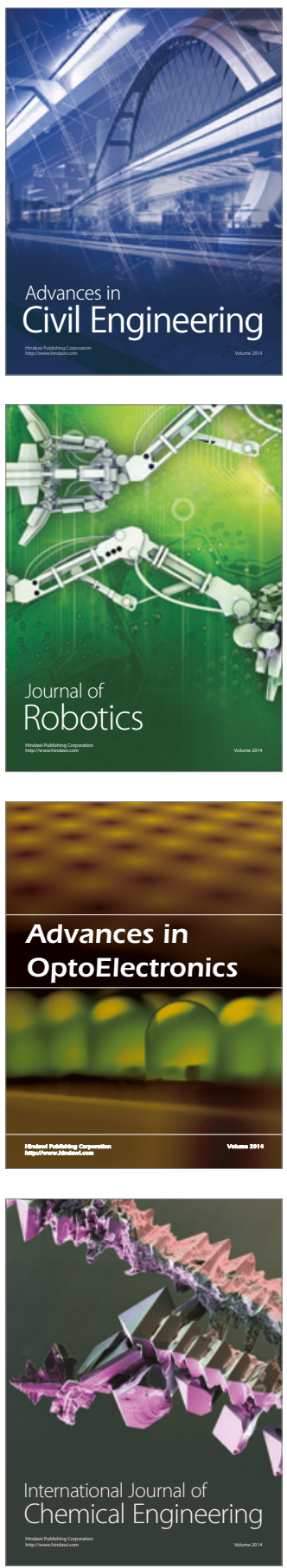

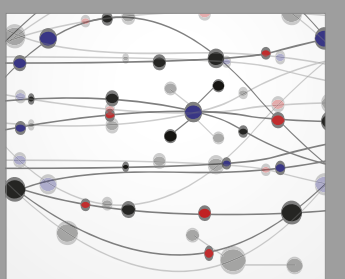

The Scientific World Journal

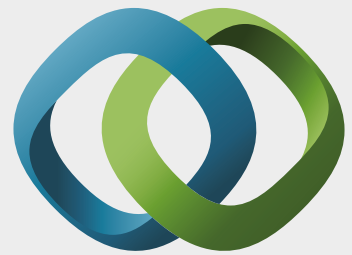

\section{Hindawi}

Submit your manuscripts at

https://www.hindawi.com
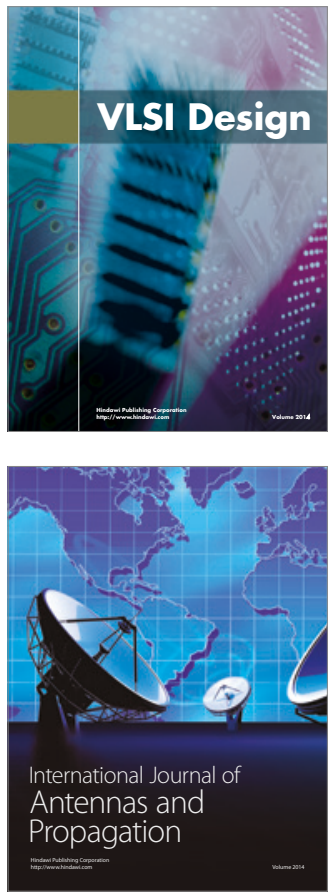

\section{Rotating}

Machinery
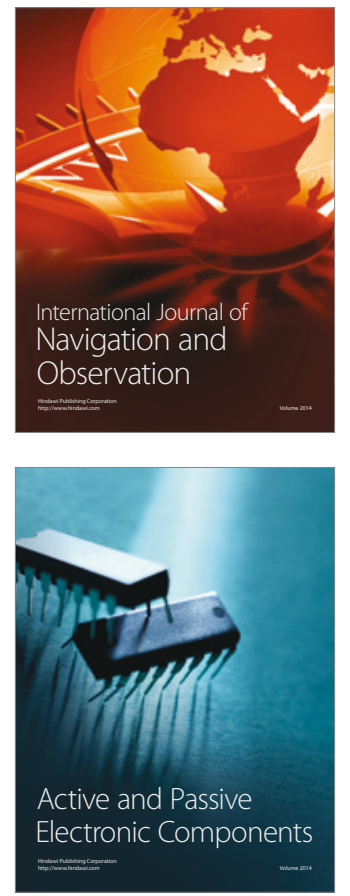
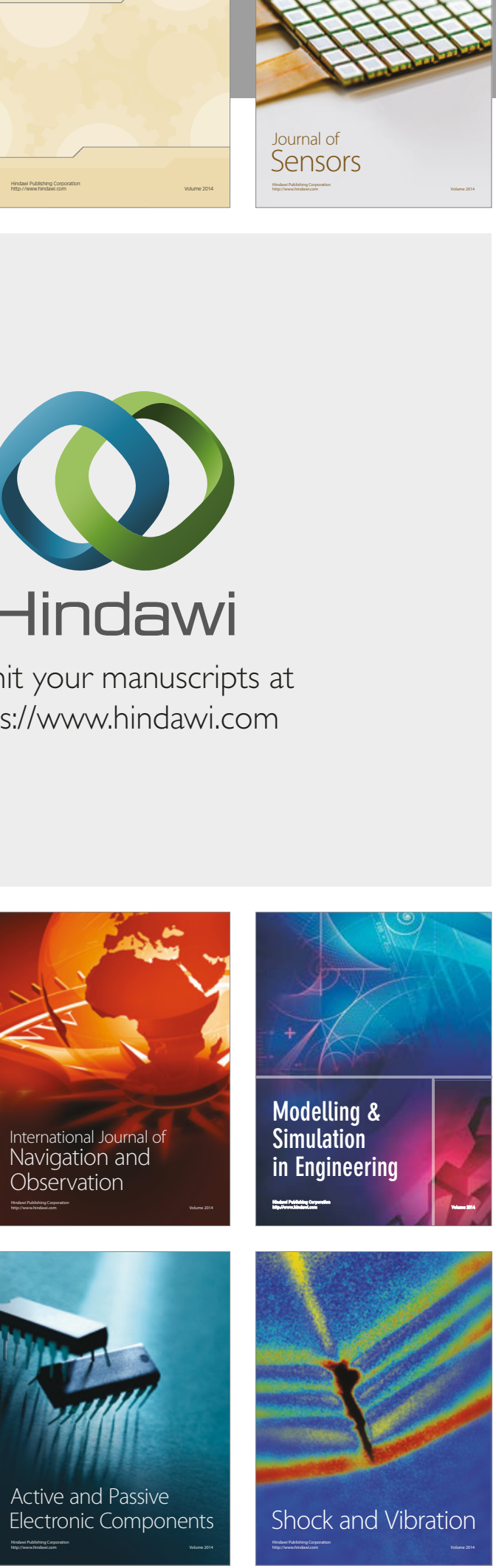
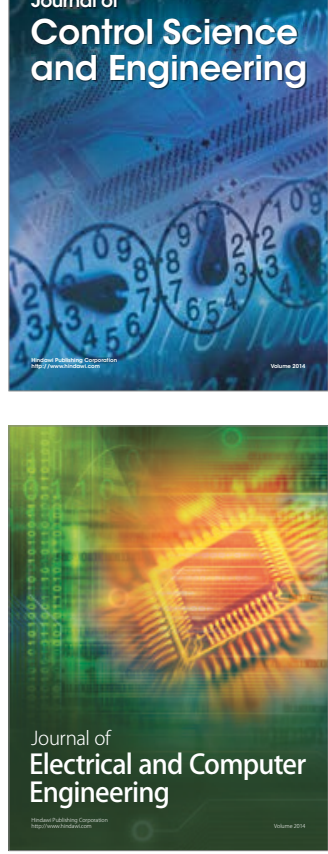

Distributed

Journal of

Control Science

and Engineering
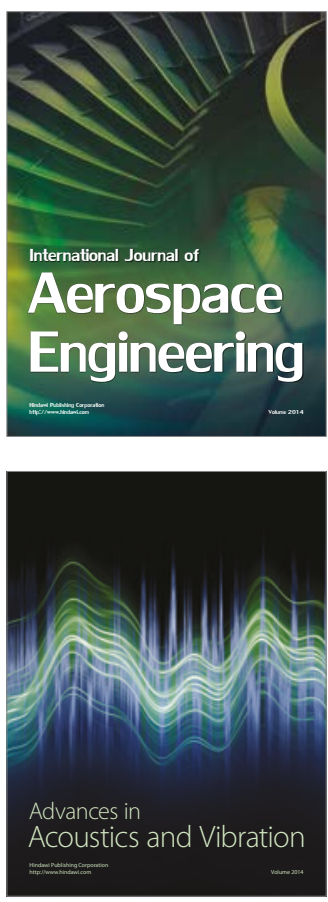

Sensor Networks 